the higher and the lower parts of the valley, and this is regarded as an important factor in the case; the cold air above presing on the warm below, and closing the pass to a sort of tube. The wind seemed to be astive only in the lower parts.

WITH the aid of delicate apparatus of recent invention Herr Grunmach (Wied. Ann. No. 9) has investigated the electromagnetic rotation of the plane of polarisation of radiant heat in solid and liquid substances (flint glass, plate glass, sulphide of carbon, oil of turpentine, distilled water, and alc shol). His finding is a: follows:- I. In solid as well as in liquid diathermanous bodies there is such rotation, and always in the direction in which the current flows through the spiral or circulates round the magnetic core. 2. The amount of this rotation is, cateris paribus, very different for different substances; the rutation is greater the greater the index of refraction of the substance. 3 . With direct action of a galvanic current conducted round the diathermanous body, the a nount of the rotation is proportional to the intensity of the current. 4. In a diathermanous body placed between the poles of an electromagnet, the amount of rotation is proportional to the magnetic force acting on the body. 5. The amount of rotation increases with the length of the substance traversed by the rays; but the relation between these two quantities could not be numerically determined.

EXPERIMENTS on heat-conduction have been lately made by M. Christiansen of Copenhagen (Wied. Ann No. 9), by the following simple method:- Three round copper plates are placed one above another, separated by small pieces of glass. A hole is bored radially into each plate, and a therinometer bulb inserted in each hole. The lowest plate rests on a brass vessel, through which cold water is conducted, and on the top plate reits a brass vessel with circulation of warm water. Through holes in the two upper plate; (supplied with copper stoppers) the intervals between the plates may be filled with liquid. $M$. Christiansea experimented first with air, and he proves that its heat-conduction increases with the temperature. The ratio of the conductivity of air to those of several liquids was next studied, the liquid being placed in the lower interval. The results agree well with Weber's figures for absolute conductivity. Some experiments were also made with plate glass (dry and wet) and marble. The method may be adapted (the author points out) to measurement of electric resistances, the potential being measured instead of the temperature.

AMONG some interesting experiments with liquid films, de s.ribed by M. Platean to the Belgian Academy, i; one in which fine iron wire is fir-t bent to represent a six-petalled flower in outline; the circular centre being supported on a small fork stuck in a piece of wood. The wire is slightly oxidised with nitric acid. The flower is dipped in glyceric solution, and is then put under a bell jar near a window, so that the sky is reflected in the films. A pretty play of bright colours is soon observed, and it continues for hours. Ag in, with regard to explosion of snap bubbles, one is apt to think the whole of the film is converted simultaneously into minute spherules. M. Ptateau has formerly shown that it is not so, and has analysed the course of the phenomenon. An experiment proving the contraction of the bubble during its quick destruction is as follows :-A bubble of glyceric liquid about II centimetres in diameter is blown with tobacco smoke, and placed on a ring. Having waited till the top appears blue, you break it there with a metallic wire, whereupon the mass of smoke is shot vertically upwards a dozen centimetres, and then spreads out hocizontally, in umbrella shape. It then rises more slowly, and is diffused.

PROF. EXNER of Vienna has lately proved that galvanic ele ments formed of three elementary subtances, one of which is bromine or iodine, give perfectly constant acion, and that the electromotive forces exactly correspond to the heat values of the chemical processes. There is no trace of polarisation. Bromine and indiue are als, shown to be the worst conductors of elec tricity at present known. Both bromine and jodine conduct entirely without polarisation, (the latter in solid as well as in liquil condition.) The conductivity rises rapidly with the temperature.

CAREFUL experiments by Herr v. Wroblewski on diffusion of liquids (three chloride of sodium solutions and water) are described in Wied. Ann. (No. 8), and yield the result that the constant of diffusion (so far as those experiments go) decreases with decrease of the amount of salt, according to a law of simple proportion. The author further tried a photometric method of measuring diffusion, where the proportion of salt is extremely small; using Hüfner's spectrophotomoter and (as colouring. matter in water) niyrosin. He cannot claim great exactness for the results, but the constant is at least one place of decimals smaller than the smallest constant of a salt hitherto known.

DR. KALISCHĖR, who has been experimenting on selenium cells for the photophone, confirms the observations of Adams and Day that lisht may in certain cases set up in these cells a photo-electromotive force; the cell becoming its own battery. The same experimenter draws attention to a curious point, namely, that the seasitiveness of seienium cells to light is often greater in cells of high resistance than in those in which, by annealing, the resistance has been greatly reduced. A single c 11 kept for some months gradually lessened in resistance, while becoming less sensitive to light. These anomalies Dr. Kalischer attribute; to the allotropic modifications through which the substance passes, the want of homogeneity accounting also for the photo-electro:notive !orces observed.

AN excellent paper by M. Gariel has appeared in our con. temporary, L'Elestricien, in which the formulæ for the grouping of cells in a voltaic battery, as deducible from Ohm's law, are dis cussed and represented in graphic diagrams. M. Gariel has thus arrived at a kind of abacus by which the variou; problems that arise may be geometrically solved by simple inspection.

Prof. Jovering of Harvard has lately unearthed from the Memoirs of the American Academy a paper by Dr. Nathaniel Bowditch of Salem, Mass., communicated in 1815 , in which he investigates the figures made by a double pendulum which compounded two vibrations at right angles to one another. This research, which was illustrated by several plates of figures, therefore antedates that of Lissajous, to whom the discovery of these figures is usually accredited, which was pulished in 1857 . Bowditch investigated the cases of the ratios representing unison, the octave, the twelfth, and the double octave. Bowditch was himself inspired to this investigation by a paper written by Prof. Dean of Burlington, Vermont, in which a comp sund pendulum identical with that known as Blackburn's pendulum, was used to illustrate the motions of the earth as viewed from the moon. Blackburn's pendulum dates from 1844 . Sang, in 1832, used vibrating wires to compound rectangular vibrations ; and Wheatstone's kaleidophone dates from 1827 .

SelF-Luminous photographs capable of shining in the dark can be made, as Eder has shown, by laying a transparent "positive" upon a sheet of Balmain's luminous paint, and then exposing the latter to sunlight. The photograph thus produced is a "positive" also. It lasts, of course," only fur a limited time.

Dr. Müller-ERzBACH, who has just made an exhaustive examination of the desiccating powers of different substances, states that there is no perceptible difference between the power of concentrated oil of vitriol, glacial phosphoric acid, and solid caustic potash in this respect, and that caustic soda and chloride of calcium are only slightly inferior, the difference in tension of aqueou; vapour between phosphoric anhydride and anhydrous chloride of calcium being a fraction of a millimetre in the barometric column. He also states that caustic soda is absolutely dehydrated by being shut up in a desiccator with caustic potash.

\section{SOLAR PHYSICS}

Lieut.-Col. Donnelly, R.E., made the following introductory remarks to Prof. Stokes' first Lecture, which was the first of the series :-

I greally regret both for your sake and my own that $I$ should have to detain you for a few minutes from the lecture which we have all come to hear. It has, however, been considered desirable that some explanation should be given of what has led to the formation of this Committee on Solar Physic;, and what has led to the giving of these Lectures. I am glad to say that in engaging your attention for a few minutes I shall not seriously curtail the time that Prof. Stokes wiil have at his disposal, for he has been good enough to undertake to lecture on Friday in place of General Strachey, who unfortunately cannot give the lecture which has been announced for him.

${ }^{x}$ Introductory Lecture by Prof. Stokes, Sec.R.S., in the South Kensington Museum Theatre on Wednesday, April 6, x88r. 
Our history commences in the year 1875 , when the Royal Commission on Scientific Instruction and the Advancement of Science made their eighth and final Report, strongly recommending the establishment, by the State, of an Observatory for Solar Physics. They say that their opinion is confirmed by the action which has been taken by foreign countries in this matter, obser. vatories for astronomical physics having been already established in various parts of Italy, while their immediate erection had been determined on at Berlin and in Paris. The Royal Commission further hoped that similar institutions might be established in various parts of the British Empire, and they particularly called attention to the great advantages that India, at certain high-level stations, affords for continuous observations, which are so important in this matter. In 1876 a very large and influential deputation from the British Association had an interview with the then Lord President of the Council, the Duke of Richmond and Gordon, with the view of urging on the Government the necessity of taking action on this and other recommendations of the Royal Commission. In replying to that deputation the Duke of Richmond pointed out that in a certain small way he had already done something in the matter, for Mr. Lockyer had been transferred from the War Office to the Science and Art Department, and facilities were being afforded him for carrying forward that portion of the researches upon this subject which he had been engaged on for several years.

The representation by the Council of the British Association was followed by a memorial from a number of eminent men of science. I need only mention, among others, the names of Adams, Andrews, Broun, Joule, Clerk Maxwell, Roscoe, and William Thomson, to show you how influential a memorial it was. They based their appeal for the formation of an observatory for astronomical physics on the fact that in the opinion of a considerable number of scientific men there was a more or less intimate connection between the state of the sun's surface and the meteorology of the earth, and they called attention to the fact that recen investigations on the part of several independent men had led them to the conclusion that there was a similarity between the sun-spot period, periods of famine in India, and cyclones in the Indian Ocean. They conclude by saying, "We remind your Lordships that this important and practical scientific question cannot be set definitely at rest without the aid of some such institution as that the establishment of which we now urge." It was under those circumstances that the Lords of the Committee of the Council of Education referred the question to Prof. Stokes, Prof. Balfour Stewart, and General Strachey for their opinion as to whether a start could not be made, and most of what is required by the memorialists in the way of daily accurate observation be accomplished by utilising the advantages offered by the chemical and physical laboratories at South Kensington with the aid of the detachment of Royal Engineers stationed there. I need not trouble you with the terms of the reference. They are given in Lord Sandon's letter of August 13, 1877, which is printed in a Parliamentary paper as a return to an address of the House of Commons moved by Lord Lindsay on March 20, 1879. I may, however, quote one sentence from it : "Although we are not at present in a position to consider the establishment of an official observatory on a comprehensive scale, we believe that some advantage can be gained if a new class of observations can be made with the means at command; since the best method of conducting a physical laboratory may thus be worked out experimentally, and an outlay eventually avoided which, without such experience, might have been considered necessary." I should also mention that Lord Sandon in his letter suggested that the Astronomer-Royal should be consulted on the subject, and he stated that "We propose to ask General Strachey to act with you especially with a view to advising us as to how far any arrangements made at South Kensington may be worked with, or form part of the system of observations which, we are informed, are in contemplation for India." Just at that particular time the Indian Government had made arrangements for having daily photographs taken of the sun's disk at Dehra-Doon in the North-West Provinces, by Mr. Meins, who, while he was a sapper in the Royal Engineers, had been trained by $\mathrm{Mr}$. Lockyer. The Committee to which I have already referred reported at the end of 1877 , and they state what in their opinion may be done at once and without entailing any serious cost. This report is also given in the Parliamentary paper to which I have alluded. Nothing however was done at that time, and in November, 1878 , the Duke of Devonshire, as Chairman of the Royal Commission on Scientific Instruction and the Advancement of Science, wrote again calling attention to the subject, and strongly urging that the Report of this Committee should be acted upon. In 1879 a small sum, 500l., was taken in the estimates for the expenses of the Committee on Solar Physics. And this has been continued ever since. As soon as that vote had been put into the estimates with the sanction of the Treasury, a Committee was formed consisting of the gentle. men whom I have already mentioned, namely: Prof. Stokes, Prof. Balfour Stewart, and General Strachey, to whom were added Mr. Norman Lockyer, Capt. Abney, and myself. The object of this Committee is to make trial of methods of observa. tion, to collect observed results, to find out what is being done in foreign countries, and so far as possible to collect and bring together all information on this subject, and finally to reduce the Indian observations which have been made since the time that Mr. Meins was sent to India. The Committee made a preliminary report last year, which was presented to both Houses of Parliament, and has been published. I therefore need not trouble you with any of the information contained in it. You will there see what the Committee has been doing, and what arrangements have been made for carrying on the Indian observations since Mr. Meins' death.

While the Committee has been thus acting in its corporate capacity, certain of its members have been carrying on independent researches of their own on different branches of the subject. The results of those researches have been published in the Proceedings of the Royal Society, but from the necessarily fragmentary manner of publication, it has no doubt been very difficult, even for men of science, to follow what was being done. Acting, therefore, on a suggestion made by the President of the Royal Society, the Lords of the Council asked the Members of the Committee to give a course of lectures which should bring in a more or less popular manner the results of their researches before the public. It is to that suggestion that this course of lectures is due. So much for the Committee. But I trust you will excuse me if I touch upon one other subject. It is now just within ten days of eighty years since Dr. William Herschel read a paper before the Royal Society which was headed "Observations tending to Investigate the Nature of the Sun in order to find the Causes or Symptoms of its Varying Emission of Light and Heat," and so on. But for the time I have already occupied, I should like to have read to you some portions of this paper, which are very striking even at the present moment. I will how ever only say now that he followed this paper by another one on May 14, I80I, on "Additional Observations tending to Investigate the Nature of the Sun in order to find the Causes or Symptoms .... and a Few Remarks to remove Objections that might be made against some of the Arguments contained in the former Paper." In those papers Dr., or, as he was afterwards, Sir William, Herschel very strongly and forcibly urges the importance of a continued observation of the sun's surface and of the sun-spots. He investigates the connection of sun-spots as far as the periods were then known, with cyclones, with the prices of wheat, and other terrestrial phenomena, and he points out of what great advantage continuous observations upon this subject were likely to be. My colleagues can tell you better than I can, and no doubt will in their lectures, what has been done in this matter since the days of Sir William Herschel. I am afraid it is not very much-I mean of course in the way of continuous observations-and yet during the interval a step has been made in the instruments of research almost, if not altogether, as great as that made in astronomy by the discovery of the telescope. I refer to the use of the spectroscope. Now, the use of this instrument, the spectroscope, so far as solar and stellar chemistry is concerned, is no doubt due to a magnificent research by Kirchhoff published in 1859 . But I think I may be allowed to call your attention to a statement made by Sir William Thomson in his address to the British Association in 1871. He there says that some time prior to the cummer of 1852 he had been taught by a certain distinguished professor at Cambridge the fundamental principles upon which this process of investigation proceeded. I need scarcely, I hope, tell you that I am not endeavouring to introduce parochialism into what should be the cosmopolitan regions of science; still less am I claiming priority for one who I am sure would be the first to repudiate such a claim. But I think you will agree with me that it is rather a striking example of the fitness of things that it is the distinguished physicist to whom Sir William Thomson referred who will give the intrcductory lecture of this course. 
Prof. G. G. Stokes, F.R.S., then delivered the following lecture :-

Some of my colleagues have applied themselves with industry and with remarkable success to various questions connected with the physics of the sun. I am not in that happy condition. I have however been requested to open this course of lectures on Solar Physics. In doing so I will touch but lightly on the labours of my colleagues, because they are going to lecture themselves, and they will be far better able than I should be to expound their own researches. As to the subject of the lecture I have pretty nearly a carte blanche before me, and I may choose my own ground. I propose to refer briefly to what is known on the subject and what speculations were made respecting the physical constitution of the sun some considerable time ago, and then to indicate how our notions gradually came to be changed.

Now I need not dwell on the importance of the sun to man. The savage knows how important it is, how man is dependent upon the sun for light and heat; but the man of science knows that, to a far greater extent than the savage can imagine, man is dependent upon that great central body of our system for almost his whole supply of light and heat. For if we want light at night, what do we do but light a candle, or whatever else it may be? If we want more heat than we get directly from the sua we light a fire; but whence comes that fire? In England we commonly use coal ; and whence came this coal? An examination of the products of the coal-fields shows that they are the remains of extinct vegetation; and if we may assume that vegetation went on in past geological ages according to the same la'ws that we observe at the present day, the supply of the carbon, upon which we are mainly dependent for the heat given out in the combustion of the coal, was derived from the air. But in the air it existed in the state of carbonic acid, to which we reduce it in the process of burning; and it was under the influence of light that, by some process the details of which we cannot explain, the carbonic acid was decomposed and the carbon appropriated. So again as regards our supply of light : if we light a candle we make use of what is derived from the fat of animals ; they are unable to decompose carbonic acid, and are dependent on vegetables for their food; so that directly or indirectly we come to the agency of the sun. We see therefore how important the sun is to man. But independently of its great importance, it presents us with features of extreme interest, which are calculated to excite the liveliest curiosity in the man of science.

The question arises, first, Is the sun always in precisely the same condition? For more than two centuries it has been known that there is 2 change in its appearance which has been observed from time to time. I allude to the dark spots which appear on its surface. Those sputs are seen to move over the disk of the sun, not with a uniform angular motion, as if there were some b ody interposed between us and the sun, and circulating around it, but nearly as if they belonged to a s slid globe rotating on its axis. I say nearly, but not quite in the same way, because it is now well established by the labours of the late Mr. Carrington, that if we attempt to determine the time of rotation of that body on the supposition that the spots were stuck to it, we obtain different results according to the place of the spot on the sun's disk. As I have said, taken as a whole the spots move nearly as they would do if they belonged to a solid globe to which they were stuck, and in that way we may determine approximately at least the direction of the sun's axis of revolution, or equator. Now Mr. Carrington found that the spots which are situated a short distance north and south of the equator, taken by them. selves alone, would indicate a more rapid period of rotation of this body than those which are situated nearer the poles. (They are never found for some considerable distance round either pole.) Associated with those spots there is another appearance called faculæ, which are ridges of extra brightness on the surface of the sun, and which have an evident relation to the spots. They are ordinarily in the neighbourhood of the spots, and moreover-and this is a point worthy of consideration with refer. ence to any theory as to the formation of the spots-it is found that sometimes faculæ will break out at the surface of the sun where there is no spot, but there is certain to be an outbreak of a spot or spots not long later. Besides this outward appearance, which can be seen with even moderately good telescope; fine telescopes show that the whole of the surface of the sun has a mottled appearance, consisting of portions, some more, so ne less, bright. It is dotted over with small specks, having the general character of minute specks of bright light. [ [Photo- graphs of the sun's surface, including a large-scale one, by Janssen, of a small portion, were here exhibited.]

These dark spots are constantly in a state of cbange, which goes on from day to day, and the finer mottlings change with very great rapidity indeed, so that $M$. Janssen found that two consecutive photographs taken quickly one after the other did not show the mottling identical; two photographs taken at the same instant did.

Now what notion can we form as to the nature of these spots? One important matter to know with respect to any speculation about their nature is, whether they are elevations or depressions. Mr. Wilson showed even in the last century, by observations of them as they changed their position on the sun's disk by the sun's rotation, that they were below, and not above, the general surface; and to the telescope they give the idea of a hole in a luminous envelope, through which you look down upon something dark beneath; and so the older astronomers adopted the notion that the sun was surrounded with a luminous envelope which they called a photosphere, and that the body of the sun itself was, not absolutely, it may be, but at any rate comparatively speaking, dark. Indeed, Sir William Herschel went so far as to speculate on the possibility of the sun being a habitable globe. How this great luminosity could possibly be kept up around a vast globe like the sun, generally dark and accordingly at a comparatively low temperature, they did not explain, and in fact you must suppose, on this hypothesis, that the true state of things at the surface of the sun is quite unlike what we have at the surface of the earth. Now we must endeavour to make our theories as to the nature of the phenomena which present themselves rest upon known laws as far as we can. Sir John Herschel, indeed, conjectured that possibly the body of the sun might be defended from the heat of the envelo, se which, as we know on earth, radiates so fiercely into space, by a perfectly reflective canopy. But where are we to get a perfectly reflective canopy? The only example we know of perfect reflection is that of total internal reflection, where rays of light or heat, as it may be, fall with sufficient obliquity on the surface of separation between a denser and a rarer medium, the rays being in the denser mediu n.

The nearest approach we know to total reflection, leaving that case out of consideration, is that of polished silver; but polished silver, although it reflects by far the large st quantity of the light falling incident upon it, by no means reflects the whole. If a globe like the sun with an envelope of polished silver were surrounded by an intensely glowing body, the globe would not remain $\mathrm{c}$ ld, at least if we are to rest upon the experiments which we can make in the laboratory. Yet this idea of a dark solid body remained in the mind of astronomers for a long time. I will read a passage from Sir John Herschel's "Outlines of Astronomy" about what the spots are :- "Many fanciful notions have been broached on this subject, but only one seems to have any degree of physical probability, viz. that they are the dark, or at least comparatively dark, solid body of the sun itself, laid bare to our view by those immense fluctuations in the luminous regions of its atmosphere, to which it appears to be subject." This sentence remained unaltered even in the edition of Sir John Herschel's work published as late as $185^{8}$.

It was, I think, in 1854, that Sir William Thomson-whom I am happy to see before me-threw out another speculation as to the nature of the heat of the sun. First I should say, perhaps, what it was not supposed to be. If we abandon the idea of a body remaining cool within an intensely glowing envelope surrounding it on all sides, and suppose that the sun is really exceedingly hot, where are we to suppose the source of that heat to be; in fact, what origin are we to attribute to the source of the heat which we know as a fact to radiate from the sun, wherever it may come from? The most natural supposition would be that of primitive heat. Take the sun, that is to say, existing as it was ages ago ; starting from that point, then, you may imagine it to be sending out heat all these ages and gradually cooling itself down. Now there would be one very strong objection to that theory if you supposed that the sun was a solid body. It might be glowing, but unless the conducting power were enormously greater than anything we have reason to suspect from experiments we can make on earth, the surface would very quickly cool down and become comparatively dark. The notion of a solid body must be given up if we suppose that primitive heat is the source. It must be at least liquid, and that liquid must be in a state of constant agitation.

Objections, however, occurred to Sir William Thomson's 
mind to such a view, and they led him to adopt another, that the heat was due to the impact of meteoric bodies falling into the sun. The surroundings of the sun may be considered to consist of a vast number of meteoric bodies similar to the shooting stars which we see when they come across the earth's atmo:phere. An assemblage of such bories reflecting in a measure the light of the sun may pos:ibly constitute the zodiacal light. Now if these bodies are continually falling into the sun their impact will produce an enormous quantity of heat. should mention that this idea had been thrown out previously by Waterton, but Sir William Thomson made an important change in it by supposing that instead of being dependent on meteric bodies casually falling into the sun from the stellar spaces, there is a supply of such bcdies circulating round the sun and gradually falling into it. He showed that the heat produced by such impacts would enormously surpass the heat of combustion of the most combutible substances we know on earth. This theory attrizutes the heat of the sun to something outside itself; w hat I may call, in contradistinction to that, primitive heat, attributes it to what is inside the sun, to the body itself. Accordilg to the mete oric theory the seat of the most intense action is at the surface of the sun itself. The old theory of a comparatively cool nucleus is here given up, ard the sun is allowed to be a glowing body, molten, doubtless; but still the most intense action is supposed to take place on the surface of the sun. With regard to the spots I think the idea of Sir William Thomcon at that time was that there were great whirlwinds at the surface of the sun from time to time which blew away these meteors, and consequently caused, where they existed, a less intense succession of impacts, and consequently less htat, and that a portion became comparatively dark. I just mention this his torically. I will not at present say anything about the very important information which the spectroscope gives us respectirg the sun, but will reserve that to a later period.

A different theory was thrown out by M. Faye in 1865. According to this the interior of the sun is intensely hot, and for that very reason, as $M$. Faye supposed, comparatively speaking non-luminous. He conceived, in fact, that the interior was so hot that bodies were there in a state of dissociation; and as we know that many a glowing gas gives out plenty of heat, but comparatively lintle light, so it was supposed that the interior of the sun, by virtue of its intense heat, radiated only comparatively little light, and that it was not until the substances of which the sun was composed came to the outside that they became cool encugh to enter into chemical combinations, and to supply us with substances which were capable of emitting an abundance of light. Now here there is one feature in common with the old views, namely, that the source of the light is supposed to be a photosphere surrounding a solid body which is, comparatively speaking, dark; but the reason why this body is supposed to be dark is precisely the reverse of that which was supposed in the older views. In the older views the body of the sun was supposed to be comparatively cool : here it is supposed to be so intensely hot that the substances of which it is composed have not yet got into a state in which they can emit much light. According to this theory the spots are places where the photosphere is, so to speak, blown away, and you see down into the intensely hot bcdy of the sun, which is conparatively feebly emissive of light. This view seemed to receive some support from a remarkable discovery made by $\mathrm{Mr}$. Huggins in 1858 with reference to the constitution of the planetary nebulæ. On applying the spectroscofe to these planetary nebula he made a remarkable dis covery, that the spectrum which they emit consists exclusively of bright lines, such as the spectrum we know to be produced by an incandescent gas. Many of these nebulæ have a somewhat stellar nucleus, which seems to exhibit a spectrum of a more ordinary character. Now at first sight this condition of things appeared to be just what the theory of $M$. Fay required, and to give an explanation of the phenomena according to that view. These planetary nebulæ give cut a feeble light compared with the stars ; and so, when seen through an aperture in the photosphere, we may suppose that the interior gaseous portions of the sun are too hot to glow with more than this feeble light.

Now that supposition is in contradiction to a very important extension of Prevost's theory of exchanges which was made in. dependently by Prof. Balfour Stewart-who is here present, I am happy to see-and by Prof. Kirchhoff. According to Prevost, if you have a body contained within a heated envelope, and everything has come to its final state, and this envelope is opaque, then all the bodies within it will be of the same tem. perature. They will receive as much heat from the walls of the envelope as they give out by radiation, and there will be a perfect balance between the radiation and the absorption. If one of those bodies is comparatively transparent, letting through a good part of the heat which it receives from the envelope, it will give out itself comparatively little heat, otherwise it would gradually become cooler. Now the extension I have mentioned is that this is true not merely of the sum total of the heat given out or absorbed, but of each particular kind of heat or light of which that total consists; so that if we take light or heat of any degree of refrangitility, there is a balance between what is absorbed and what is given cut.

Now this extension of Prevost's theory militates against $M$. Faye's theory of the constitution of the sun as regards the constitution of the spots. For, take the interior of the sun. If we take light of any particular degree of refrangibility, the bcdy, that is, this supposed gas which constitutes the bulk of the sun, will be either opaque as regards that kind of light, or transparent, or partially transparent. If it is opaque it is certain to emit light of the same refrangibility. If it is transparent, then the ?pot would rot be dark, because, as regards any kind of light for which this interior gas was wholly transparent, we ought to see the oppo:ite side of the photosphere shining through; just as in the planetary nebula we do see what we have every reason to supfose to be a nucleus of the nebula shining right through its enorm us semi-diameter. The stars s ubtend no appreciable angle, but the plaretary nebulæe subtend a very appreciable angle, which can be neasured, and in all probability, judging by the distarce of the planetary netulæ from us, their dimensions are gigantic as compared with the average size of the stars, and as compared in all probability with our own sun. Therefore there ought to be seen in the sun, on that supposition, the same phenomencn as is seen in these planetary nelula, namely, the photosphere on the far side shining across the gaseous globe. It seems to me that that consideration is fatal to the acceptance of M. Faye's theory as a whole, and that we must have recourse to some other.

Now I have mentioned already Sir William Thomson's meteoric theory, in which is involved the very important consideration of the conver: ion of work into heat. I do not mean at all, in stating some possible objecticns to that theory (which he has hime elf since given up), to go against the supposition that the original source of the sun's heat may have been the conver:ion of work into heat, but starting with the sun as it was some ages ago, has the subsequent heat been derived from itself, or from the outside? According to the theory of M. Faye, the heat would ke derived from the sun itself, which would be spending its heat gradually. So far (giving my own view as to $\mathrm{w}$ hat is probable) it scems to me that the probabilities are in favour of that part of the theory. Well then, if the spots are not due to the dark body of the sun being exposed by something being removed from the outside, te it that the body is dark from a deficiency of heat or from an excess of heat, what may we suppose them to be? In a paper fublished in the Philosophical Transactions by Messrs. De La Rue, Stewart, and Löwy, the autbors bave advocated the view that the spots are due, not to an upising from the centre of the sun, but to a down-prur of ccoler pertions of the matter which has teen ejected from the sun. But here I think I cannct go on without going back to some researches in which the spectroscope plays a most important part. It is to Prof. Kircbhoff that we owe the first extensive application of the spectroscope to the study of the sun. He held that since bodies in the state of incandercent gas give out bright lines in their spectrum, according to the extension which he made, independently of Prof. Balfour Stewart, of Prevost's theory of exchanges, these glowing gases ought to absorb light of the same refrangibility coming frem a body behind. Now if you had a glowing as in front of an of aque body glowing at the same temperature, you ought to see neither dark nor bright lines, for the gas would absorb the light of the refrangibilities which itself gives out, and it would not absorb the light of the $r \in$ frangibilities which it does not give out, so that in the region of the bright lines we should, even if the body behind were away, get the full amount of light due to the temperature, coming from the glowing gas itself; in other regions where there is no such bright light coming from the gas, you get the full amount of light coming from the opaque bcdy behind. But if you suppose this gas in front, glowing though it be, to be at a lower temperature than the opaque body behind, then it would absorb more light of the 
kind which it gives out coming from the body behind than it gives out to replace it by virtue of its own emission, and accordingly we should see the place of those bright lines, or what would be bright lines if the gas were there alone, dark on a bright ground. By following out that theory he was enabled to identify a great number of the daik lines in the solar spectrum with the bright lines given out by elements which we know at the surface of the earth, such as iron, magnesium, and so forth. Now this throws a most important light on the constitution of the sun. It indicates that even in the outer, and, comparatively, therefore cooler portion of the sun, there must still be a temperature so enormous as to be above the boiling-point of iron, and above the boiling point of some of the most refractory metals. And now I will refer to a later application of the spectro cope which was made by a gentleman whom I see before me. First I should say that in the year 1842 , in observing a total solar eclipse, a new pheno nenon was witnessed, or at least a phenomenon which, if not new, had not previously attracted general attention. The dark body of the moon was seen to. $b$ z surounded by rosecoloured prominences having the appearance of mountains. What were these? What could possibly be their nature? We had but a small time to observe them; the greate it duration of a total eclipse of the sun is a little over four minute;, and these eclipses occur only once perhaps in two years or so, and when they occur the totality extends over a strip along the earth's surface of only inconsiderable breadth, with probably a great portion of it falling on the ocean, so that if we were there present in a ship we could hardly make any observations but what could be taken by the naked eye. The study of these prominences and the nature of them must have been therefore a slow matter to get on with, so long as we were limited to the observation of them during the period of a total eclipse. The change of height of those prominences shows that they belong not to the moon, but to the sun. Of course, as the moon moved over the body of the sun they would, if they belonged to the sun, tend to get shorter and shorter as they were covered in, and would reveal themselves gradually in the same way behind the opposite side, which is just what happened. In 1860 special provision was made for the observation of these prominences, and Mr. De La Rue undertook to make a series of photographs, which led to so se most important results. They showed, among other things, that in some cases the prominences, whatever they were, were not at all attached to the body of the sun, but were suspended as clouds around it. They could not, therefore, be mountains clearly. Mr. Lockyer, for some considerable time prior to 1868 , had been devising in his mind a possible mode of rendering those prominences visible, and studying their nature without waiting for or being dependent upon the rare phenomenon of a total eclipse. If the light which those prominences gave out consisted of bright lines, then, by applying a spectroscope of high power to the study of those bodies, we might so far reduce the intensity of the intervening portions of the spectrum where there is the diffused light coming from the immediate neighbourhood of the sun's disk as to render them visible. At last he was rewarded by success, and the announcement of this discovery was made to the Royal Society. Meanwhile M. Janssen had gone out to India to observe a total eclipse, and the special subject which he took up was to observe the spectrum of those prominences, which he did with success. The idea struck him, "Why should not this be done any day?" $\mathrm{He}$ tried, and the next day he succeeded. In point of ab olute time this was before the observation of Lockyer, although at the time no account of it had reached this country, so that the two observations were perfectly independent of each other. Well, subsequent improvements in the method of observing those prominences have enabled us to see them at will, so that they may be observed from day to day, when we choose, from hour to hour, from minute to minute. The forms of them can be seen, and it is found that they move with astounding velocity. They are projected upwaris from the sun with a velocity sometimes of 100 or even of 140 miles per second. Their forms were such as we might naturally attribute to the ejection of gas from the body of the sun. It had been conjectured that they might be of the nature of auroral discharges. Their features however indicate that they are projections of actual matter from the sun, and moreover the nature of their motion indicates the same. This gives us, then, a new idea of the vastness of the changes which are continually going on at the surface of the sun.

Now what is the origin of these changes? It seems to me that the most reasonable idea that we can form respecting them is something derived from what takes place in our own earth, and what we can observe here. Suppose the sun to be shining, we will say on a summer's day. If we look horizontally with a telescope everything is seen to be in a state of tremor; the air is far from homogeneous. What is the reason of that? The greater part of the sun's heat passes through the upper strata of the atmosphere and reaches us, the air being tran'parent with regard to a large portion of the sun's heat. It warms the sur. face of the earth. That in turn warms the air in contact with it, and further radiates forth heat of a kind for which the air is opaque. The consequence is that the lower portions of the air in contact with the earth get warmer, and that unequally according to the nature of the ground-more on stones and gravel, for instance, and less on grass and so forth. Being warmer they get lighter, and therefore there is a constant ascent, a constant mixing of the hot and cold portion; by currents of convection. As this goes on continually a stratum of air of considerable height becomes warmed in this manner, and some. times an exchange by convection or something of the nature of convection takes place on a very grand scale. Let us take the case of summer weather. Suppose we have a succe sion of hot days accompanied by a good deal of evaporation, gradually these several currents of convection cause a warmin $x$ of a stratum or air below of considerable height, which is also well supplied with moisture from the evaporation. At last, taking the stratum as a whole, the equilibrium becomes unstable, and there is an up. rush; hence there is a kind of chimney formed, through which the air flows upward;, and then spreads out laterally overhead. This appears to be what takes place in our summer thunderstorms. The heated and moist air forms for itself a chimney, and in ascending there is a rapid deposition of what was previously vapour of water in the now condensed state of water itself, and a rapid fall of rain occurs after a time Thi i appears from some cause or other to be the occasion of the development of a great deal of electricity, which is manifested in the form of lightning. While this action goes on you have the in-draught towards what I will call the chimney from all sides; the vapour sooner or later gets condensed, and there is a fall of rain accompanied by lightning. Sometimes there is hail even in sum ner; for when the air charged with vapour gets to a particular height the vapour becomes condensed and forms rain ; but it may be that the stratum of the $u_{p}$ per air that is pierced through is below the freezing-point, and, the rain falling through this, it gets frozen. I will just call attention to one fact; according to this view, you see you may have a general current of wind over the country-say, for the sake of illuitration, from west to east. Suppose there is a region to the west where an ascending current has been forme 1 ; then there is an in-draught from all sides to that place, and when the thunderstorm has not yet come on you are in a comparative calm, because the general direction of the wind being from the west, and the in-draught carrying the air from the east, the two together tend to neutralise one another; or you may have actually a wind blowing towards the region of the thunderstorm. Accordingly we know people often say that thunderclouds move against the wind. I shall have occasion to refer in my next lecture to the development of atmospheric electricity in reference to some speculations in regard to phenomena accompanying changes in the condition of the sun but at present I merely refer to this process as illustrative of what seems to be the most natural supposition to make regarding the origin of these disturbances which are found to be continually taking place at the surface of the sun. The outer portion; of the sun are the source of a gigantic amount of radiati on of heat and light which passes out in all directions. By this radiation those outer portions must tend to a certain extent to cool down, and consequently, as the same physical condition: holl good, if the same physical laws hold good, at the surface of the sun that we have on our own earth, you may easily suppose that, having become cooler than they were, the substance; become specifically heavier, and accordingly give rise to curents of convection similar to those that we have in our own atmo:inhere from a sinilar catse, but operating in one respect in a different way, because in the solar atmosphere there is a cosling from above, but in that of the earth a heating from below. Those minor currents of convection ascending and descending naturally enough give rise to that mottled appearance which is always seen on the sun's surface, because if the interior of the sun be hotter than the portions which have cooled ny radiation, then the ascending portions would naturally, being at a higher tem. perature, be brighter, the descending portions darker, and small 
(comparatively speaking) descending currents may very likely, as it appears to me, be the cause of these appearances. Now just as at the surface of the earth these minor currents of convection are continually going on, and mixing up the heated portions below with less heated portions. above, till at last a great catastrophe takes place, and we bave a thunderstorm or even a cyclone; so the same thing may take place at the surface of the sun, and minor currents of convection may gradually cause a cooling of a greater stratum, and at last the equilibrium hecomes unstable, and a great change takes place between the superficial portions and those $\mathrm{which}$ lie beneath, and we have the manifestations of faculæ and spots. According to this 'view the faculæ would consist of the heated portions on a larger scale coming from the interior, and the spots of a subsequent down-rush on a large scale of the portions which had been erupted and had cooled by radiation. Kirchboff supposed that the spots were due, not to depressions of the sun, but to clouds of comparatively cool gases or vapours rising above the general surface. This was in contradiction to the relative altitudes of the sun-spots and the general surface as made out originally by Wilson, and subsequently confirmed by the observations of others ; and moreover there are some other difficulties connected with it. Let us suppose that there is an eruption of bydrogen which has got cool, then if that exists and there is a cold draught at some distance above the sun, we cannot say it would absorb any longer the rays which it is capable of absorbing when glowing, because the correspondence of emission and absorption only necessarily holds good on condition that the substance is at a given temperature. If the temperature changes it is possible, and in many cases we know it is a fact, that the mode of absorption may cbange with it. We know that the cold hydrogen is transparent; we know, theoretically at any rate, that glowing hydrogen must be opaque with regard to light of the particular refrangibility which it emits; bence a cool mass of gas might cease to be opaque even by virtue of its being cooled. Again, if we had a cloud of, say, vapour of iron, and if this were condensed into actual drops or globules of molten iron in the upper portion of the atmosphere, they would form such a very rare sort of mist as would be something like a very rare haze which barely obscures the sun, and would not give rise to more than a slight general darkening. But if the gases in descending got warmed again, they would then be in a condition to absorb light specifically; but being at a lower temperature than the sun they would not give out nearly so much light as they absorb.

That seems to me to be the most natural explanation of the spots and of the phenomena attending them. I may have some thing more to say about this on a future occasion; but, as I see the time is going on, it would probably be more agreeable to you that I should postpone anything further I have to say to you upon this subject until my next lecture, in the course of which I hope, as I have said, to point out a speculation as to the connection which exists between sun-spots and certain phenomena which we know exist at the surface of the earth. There are probabilities to my mind in favour of it, but I will, with your permission, defer allusion to it to my next lecture.

( $T$ o be continued.)

\section{THE HELVETIC SOCIETY OF NATURAL SCIENCES}

THIS Society held its sixty-fourth annual session at Aarau on August 8, 9, and Io, under presidency of Prof. Mühlberg, whose opening discourse treated of recent progress in physiology and chemistry. An account of the proceedings (of which we here offer a brief résumé) will be found in the Archives des Sciences.

In the Section of Physics and Chemistry Prof. Forel read a valuable paper on the periodic variations of glaciers. These periods of advance and retreat are proved to embrace several years (five to twenty and more); they are due in the first instance mainly to variation in velocity of the glacier, and this to small variations in the thickness of the néve repeated in the same sense for several years, the consequent variation of velocity becoming much more pronounced as the glacier descends, and the ultimate effect being separated by many years from its original cause. The varying heat of summer appears to be of quite secondary importance. In one of three papers, communicated by $\mathrm{M}$. Raoul Pictet, he described his new method of distillation and rectification of spirits by a rational use of low temperatures.
The two processes are performed at once; and with considerable economy a purer product is obtained. Another pape: explained the principle of his rapid steamer, now being made, and the working of which will be watched with interest. The third treated of the different qualities of steel as regards magnetisation and permanence of magnetic power. (To this and the preceding, reference bas been already made in our columns.)

M. Krippendorff exbibited a model of a balloon, to be propelled in light winds by escape of compressed air at the end of a wooden axis rendered horizontal or inclined according to the direction aimed at (by shifing the suspension of the car). The air would be compressed by four men into a small copper receiver at the other end of the axis; and a second reservoir holding liquid carbonic acid would be at band in case of need. In a micro-telephone described by Prof. Amsler-Laffon, the flame of a manometric cap:ule (like those of König) is inserted in a telephone circuit; its conductivity being increased with vapcurs of lotassium. Its change in form and size through vibrations of a thin plate of steel under sound, entails changes in electric resistance, and the telephone is affected acrordingly. The apparatus is said to be very sensitive. Some useful hints on representation by projection of In ngitudinal and transversal vibrations are given in a paper by Dr. R. Weber. MM. Soret and Sarasin indicated a new method of determining the angle of rotation of quartz, and showed, in a curve, how the rotatory power varies with the wave length.

An interesting observation is reported by Prof. Dufour, who finds in deformation of images produced on large surfaces of calm water, a new proof of the roundness of the earth. This may often be witnessed on the lake of Geneva, e.g. the reflected steeple of Montreux, seen from Morges; and in the case of ships some kilometres distant at sea. Prof. Forel, from a study of the recent earthquakes in the Cantons of Vaud and Neuchâtel, finds analogies to the phenomena of a vibrating plate in Chladni's experiments; the intensity and direction of a shock, e.g. being very different in places quite near each other. Guided by theo" retical considerations, $\mathrm{M}$. Chappuis has measured the liberation of heat through condensation when water is introduced suddenly into an evacuated tube filled with charcoal in temperature equilibrium with the water, and from the data, and the compres:ibility of water he infers the adherent water to be under a pressure of at least 36 million atmospheres. Among other subjects discussed were the measurement of radiant heat with the differential thermometer (Dufour), the determination of tartar and tartaric acid in wines of commerce (Piccard), and the action of bromine on a mixture of water and sulphide of carbon (Ureck).

In Zoology M. Fatio gave some account of his continued researches on disinfection with sulphurous acid. The vapours act in two ways on all ofganisms which depend on oxygen for Jife, viz. asphyxiating them by suppression of that element, and gradually burning them interiorly, the acid being dissolved in their humours or aqueous parts; the doses and times of application are varied accordingly. The more aqueous in substance an animal or plant is, the more quickly is it affected. The dose and time of application, in different receivers, will also be varied according to the temperature affecting diffusion of gas and the hygrometric state of the air and enveloping material. M. Fatio operated successfully on vibrions and bacteria in infusions submitted to an atmosphere mixed with sulphurous acid (the depth of the liquid here cletermines the time of exposure), and the range of application is evidently wide. M. Vogt gave some interesting facts showing the extensive adaptation of colours in animals of the Saharan Desert to that of the ground. With regard to the exceptional colour of nearly all Coleoptera, viz. black, he considers they find protection in their bad smell, and also their strong resemblance, when contracted and feigning death, to excrement of gazelles, goats, and sheep. The animals brought to the surface by water of Artesian wells in that region M. Vogt finds to be quite without the characters of animals living in caverns and subterranean water; their eyes are well developed, and their colours pronounced. They are indeed proved to live but temporarily underground. With albumini:ed paper Prof. Forel fixed 40 metres as the limit of penetration of chemical rays into water, but Dr. Aspen has, by a different method, got a photographic effect in the Lake of Zurich as far. down as 90 metres. The researches of Mr. Yung on the influence of food on frog development have been formerly noticed; and of the remaining subjects we merely note the sense of colour in Cepha. lopoda (Keller), a peculiar mode of copulation in dendrocœle marine worms (Lang), and the conditions of production of 